\title{
Novidades em nossas normas para submissão e publicação de artigos
}

\author{
Alcimar Barbosa Soares, $\mathrm{PhD}$ \\ Editor-Chefe
}

Este primeiro fascículo de 2013, a exemplo de outras edições, traz novidades importantes para todos. Na busca incansável pelo crescimento da revista, pela alavancagem de sua projeção nos cenários nacional e internacional e principalmente, pelo crescente desejo de tornar a RBEB um veículo que contribua cada vez mais com o desenvolvimento científico e tecnológico nacional e internacional, o corpo editorial da Revista promove, a partir desta edição, mudanças significativas nas normas gerais para submissão e publicação de trabalhos.

Em primeiro lugar, decidiu-se pela extinção da seção destinada à publicação de resumos de teses e dissertações. Planejada como um mecanismo de divulgação dos programas de pós-graduação brasileiros, essa seção já não apresenta mais um impacto significativo para nossos programas e para a comunidade em geral. A demanda por publicações qualificadas, resultantes de trabalhos de pós-graduação, tem feito com que os autores tratem de publicar seus trabalhos no formato de artigos completos em periódicos ou congressos científicos, reduzindo a importância da publicação dos resumos de suas teses e dissertações em outros meios, além das próprias monografias.

Também foi eliminada a possibilidade de submissão e publicação de tutoriais. De fato, esta modalidade não tem sido utilizada pela comunidade. Talvez porque a imensa gama de mecanismos disponíveis na internet (redes sociais, sistemas de publicação online de vídeos e mídias diversas etc) tenha tornado a divulgação de tutoriais mais dinâmica, simplificada e até mesmo interativa.

Assim, a Revista Brasileira de Engenharia Biomédica passa agora a receber apenas submissões de Artigos Originais, Artigos de Revisão, Comunicações Técnicas e Cartas ao Editor.

$\mathrm{O}$ formato dos artigos de revisão será mais livre. De agora em diante, estes manuscritos devem ser formatados com as seções: (i) Título e informações sobre os autores; (ii) Abstract estruturado conforme as seções principais do corpo do texto (ex: Introduction, Methods e Conclusion) e seguido de keywords representativas do conteúdo do documento; (iii) Resumo (apenas para artigos submetidos em português) estruturado conforme as seções principais do corpo do texto (ex: Introdução, Métodos e Conclusão) e seguido de palavras-chave representativas do conteúdo do documento; (iv) Revisão/Review - corpo do manuscrito, que pode ser dividido em seções e subseções, a critério dos autores; (v) Agradecimentos; e (vi) Referências.

O corpo dos artigos originais e das comunicações técnicas também sofreu alterações. A partir de agora, eles devem ser estruturados da seguinte forma: (i) Folha de rosto com título, autores etc; (ii) Abstract estruturado com as subseções 'Introduction', 'Methods', 'Results' e 'Conclusion', e seguido de keywords representativas do conteúdo do documento; (iii) Resumo (apenas para artigos submetidos em português) estruturado com as subseções 'Introdução', 'Métodos' e 'Conclusão', e seguido de palavras-chave representativas do conteúdo do documento; (iv) Introduction/Introdução; (v) Methods/Métodos; (vi) Results/Resultados; (vii) Discussion/Discussão: apresentando uma avaliação crítica dos resultados e sua associação com os conhecimentos existentes na literatura, bem como as principais contribuições do trabalho; (viii) Acknowledgments/Agradecimentos; e (ix) References/Referências.

Notem que foram extintas a seção "Extended Abstract" (até então exigida para os artigos submetidos em português), em favor da inclusão de resumos e abstracts estruturados, e a seção "Conclusão" (as principais contribuições científicas do trabalho e sua relevância em relação ao atual estado da arte devem ser apresentadas ao final da seção Discussão). 
Outra alteração importante, que está sendo avaliada cuidadosamente pelo corpo editorial, refere-se ao formato a ser adotado como padrão para as referências e citações. Esta é uma questão de grande debate e envolve desde preferências e estilos pessoais à questões associadas às demandas e padronizações adotadas pelas grandes bases de dados e seus mecanismos para rastreamento de citações. Estamos avaliando os diversos padrões existentes em busca daquele que melhor se enquadre às demandas de nossa Revista e de nossos autores, atuais e futuros.

Mas, a maior e mais impactante mudança está planejada para 2014. Após intensos debates entre os colegas do corpo editorial da RBEB, da diretoria e do conselho da SBEB, decidiu-se que a Revista passará a publicar apenas artigos escritos em inglês.

Os debates tiveram como pano de fundo uma questão central: de que forma a RBEB pode melhor servir à SBEB e à Comunidade de Engenharia Biomédica?

Uma das questões que sempre esteve presente foi a possível dificuldade de muitos jovens autores em redigir adequadamente textos na língua inglesa. Contudo, percebemos uma ampla gama de opções que poderá minimizar esse problema, como, por exemplo, os vários serviços de tradução especializados, e de qualidade, que podem ser contratados, até mesmo via internet, à custos relativamente baixos. Outro ponto interessante é que a maioria das universidades conta hoje com contratos de serviços de tradução à disposição dos estudantes e docentes de seus programas de pós-graduação - uma parte significativa do público atual da RBEB. Além disso, sempre existirá a possibilidade de buscarmos recursos para que a RBEB contrate serviços especializados para revisão final dos textos.

Nosso recente ingresso em grandes bases de dados (como SCOPUS e SciELO) possibilita que artigos redigidos em inglês sejam lidos por uma quantidade muito maior de pesquisadores. Os reflexos disso seriam o aumento das citações, com benefícios diretos para os autores, e, em consequência, a elevação do fator de impacto da RBEB. Um maior fator de impacto, por sua vez, poderá implicar ainda em mudanças de nosso "Conceito Qualis" - um importante elemento para a comunidade SBEB atuante nos programas de pós-graduação do país (hoje somos conceituados como B1 nas áreas de Engenharia IV e interdisciplinares - que congrega a maior parte de nossos autores e leitores).

Outro aspecto interessante é a possibilidade de aumentarmos significativamente nosso corpo de revisores internacionais. Com o aumento do volume de submissões observado nos últimos meses, nossos editores estão enfrentando grandes dificuldades para a definição de revisores qualificados - note que, para cada artigo submetido devem ser convidados de dois a três revisores qualificados no assunto. Esta é, inclusive, a razão principal para demora na emissão de muitos pareceres. Por fim, este possível aumento nos quadros, além do aspecto quantitativo, poderá também implicar na melhoria da qualidade de nossos artigos, uma vez que pesquisadores de praticamente todas as regiões do planeta, com visões e experiências diversas, poderão participar do processo.

Ciente de que esta transição implicará em grandes mudanças para alguns de nossos autores, bem como envolverá ajustes importantes no processo de gerenciamento da revista, o corpo editorial decidiu que a transição para "monolíngue_inglês" se dará de forma gradual e conforme as seguintes etapas: (i) Iniciamos agora uma ampla campanha de divulgação para toda a comunidade; (ii) A partir do segundo semestre de 2013 (edições 29(3) e 29(4)), a RBEB dará prioridade para publicação de artigos redigidos em inglês, sendo possível a publicação de artigos em português de excelência ou que tenham sido aprovados até junho; (iii) A partir de outubro de 2013, a RBEB só aceitará submissões de artigos redigidos em inglês; e (iv) A partir da primeira edição de 2014, a RBEB publicará apenas artigos redigidos em inglês. Possíveis artigos redigidos em português e ainda não publicados até dezembro, deverão ser traduzidos para publicação nas edições de 2014. Estamos estudando também a possibilidade de publicação de uma edição extra para dar vazão a artigos aceitos, redigidos em português, e não publicados até o final do ano.

Entretanto, sabemos que essas são mudanças importantes e com forte impacto para Revista e para nossa comunidade. Desta forma, CONVIDAMOS A TODOS para se manifestar em relação a estas e outras questões. Usem nosso email rbeb@rbeb.org.br para opinar e enviar sugestões.

Como destacamos anteriormente, o que se busca com estas e outras medidas é o aprimoramento contínuo da RBEB, tornando-a, cada vez mais, um veículo para publicação de trabalhos de qualidade e que impactem significativamente na pesquisa nacional e internacional. 